\title{
Im sozialen Netz
}

In kurzer Zeit sind Soziale Medien wie Facebook zu einer Selbstverständlichkeit geworden. Viele Menschen organisieren ihre gesamte Freizeit in diesen Netzwerken. Wer nicht drin ist, ist nicht dabei, ist von der Kommunikation ausgeschlossen. Das gilt zunehmend auch für Unternehmen. Die Frage ist längst nicht mehr, ob man sich mit diesen Medien auseinandersetzen muss, sondern wie? Was ist sinnvoll, was nur ein kurzlebiger Hype? Was für ein Unternehmen ein „Muss“ ist, kann für andere überflüssige Geldverschwendung sein.

Eines sollte klar sein, Mitarbeiter sind aus ihrer Freizeit da-

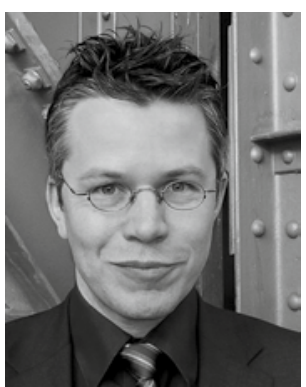

Peter Pagel

Chefredakteur ran gewöhnt, Soziale Medien zu nutzen. Sie werden dies auch im Unternehmenskontext tun. Deshalb ist es entscheidend, dass überall da, wo es wichtig ist, dass nicht über öffentliche Plattformen kommuniziert wird, interne Alternativen durch die Firmen-IT zur Verfügung gestellt werden - etwa, um Termine in lokal verteilten Teams bequem organisieren zu können. Zudem ist es oft sinnvoll, auch öffentliche Plattformen zu nutzen, dann ist es wichtig, den Mitarbeitern klare Regeln zum Verhalten zu geben. Sicher ist, dass sich unser privater und beruflicher Alltag durch Soziale Medien in relativ kurzer Zeit deutlich verändert hat; das merkt man unter anderem daran, wie selbstverständlich deren Nutzung für sehr viele inzwischen ist. Die Erreichbarkeit via Facebook ist für eine wachsende Gruppe von Menschen wichtiger als ein Festnetztelefonanschluss - den haben viele der jüngeren Generation schon lange nicht mehr.

Viele Grüße,

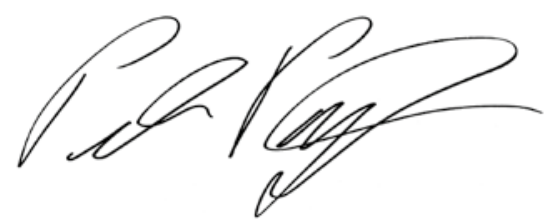

Peter Pagel, Chefredakteur 